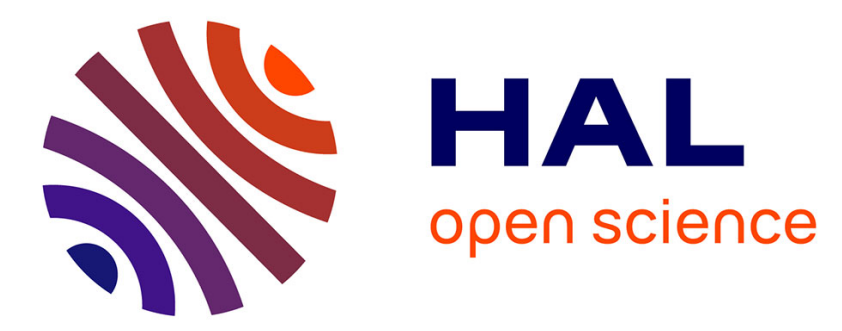

\title{
Magnetic Forces and Vibrational Behavior Analysis for Flux Switching Permanent Magnet Machines
}

\author{
Julien Boisson, François Louf, Xavier Ojeda, Xavier Mininger, Mohamed
}

Gabsi

\section{- To cite this version:}

Julien Boisson, François Louf, Xavier Ojeda, Xavier Mininger, Mohamed Gabsi. Magnetic Forces and Vibrational Behavior Analysis for Flux Switching Permanent Magnet Machines. ICEM 2012, Sep 2012, Marseille, France. pp.2988-2993, 10.1109/ICElMach.2012.6350313 . hal-00779589

\section{HAL Id: hal-00779589}

https://hal-centralesupelec.archives-ouvertes.fr/hal-00779589

Submitted on 22 Feb 2022

HAL is a multi-disciplinary open access archive for the deposit and dissemination of scientific research documents, whether they are published or not. The documents may come from teaching and research institutions in France or abroad, or from public or private research centers.
L'archive ouverte pluridisciplinaire HAL, est destinée au dépôt et à la diffusion de documents scientifiques de niveau recherche, publiés ou non, émanant des établissements d'enseignement et de recherche français ou étrangers, des laboratoires publics ou privés.

\section{(ㄷ)(1) $\$$}

Distributed under a Creative Commons Attribution - NonCommerciall 4.0 International 


\title{
Magnetic Forces and Vibrational Behavior Analysis for Flux Switching Permanent Magnet Machines
}

\author{
Julien Boisson ${ }^{1}$, François Louf $^{2}$, Javier OJedA $^{1}$, Xavier Mininger $^{3}$, Mohamed GAbsi ${ }^{1}$ \\ ${ }^{1}$ SATIE, ENS Cachan, CNRS, UniverSud, 61, av President Wilson, F-94230 Cachan, France \\ ${ }^{2}$ LMT, ENS Cachan, CNRS, UniverSud, 61, av President Wilson, F-94230 Cachan, France \\ ${ }^{3}$ LGEP, CNRS, 11 rue Joliot Curie, F-91192 Gif sur Yvette, France
}

This paper deals with the magnetic forces and the mechanical behavior of flux switching permanent magnet (FSPM) machines. First, we will focus on the origin of magnetic stresses in the FSPM machine. Secondly we will realize a FEM analysis to observe these stresses in two locations (at the air / teeth interface and at the permanent magnets / iron interface) when the FSPM machine is unloaded and loaded. Then, we will consider the expression of the stator deformation. Finally, eigenmodes of this structure obtained by FEM analysis will be presented and compared to experimental measure.

Index Terms-Flux Switching, Permanent Magnet Machines, Vibration, Magnetic Stress, Finite Element, Modal Analysis

\section{INTRODUCTION}

$\mathbf{T}$ HE flux switching permanent magnet (FSPM) machine is an electromechanical converter with all the active elements located on the stator. The rotor is composed by ferromagnetic sheets. This structure leads to a greater torque density. Besides, as permanent magnets are not located on the rotative part, the machine is able to revolve with higher speed [1]. All thermal sources are on the static parts and permit a much more efficient thermal evacuation [2] [3]. However, this structure exhibits a major drawback: the stator teeth have to be thin in order to mount the magnets and, as a consequence, it leads to a high local magnetic induction. It also creates a high magnetic stress and finally, significant acoustic vibrations, which have to be added with aerodynamic and mechanic noise.

Nowadays, studies dealing with magnetic vibrations in the machines concern simple structures, i.e. one-piece stator with no magnet. The best example of such structures is the switched reluctance motors (SRM) [4] [5]. Thus, most of the publications focus on deformations of the stator teeth. The FSPM machine presents a more complex structure induced by the presence of magnets in the stator. Also, even if the study of stresses located on the teeth remains relevant, it seems wise to also determine the force appearing in different locations and particularly at the magnets / iron interfaces.

This paper offers an analysis of magnetic vibrations in FSPM machine. First, the machine and notations will be introduced (II). Then, the magnetic stresses in two locations (at the air/teeth interface and at the permanent magnets/iron interface) will be presented (III). Then a modal analysis of the stator will be developed (IV).

\section{12/10 FSPM MACHINE}

The operating principle of FSPM is introduced in Fig. 1. When a rotor pole is aligned with a stator pole as in Fig. 1 (a), flux of coil is positive maximum. When a rotor pole is aligned with a stator pole as in Fig. 1 (b), flux of coil is negative maximum.

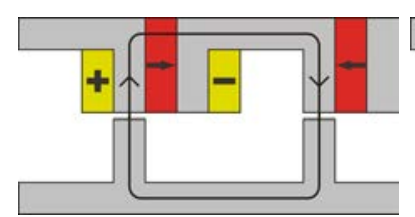

(a) Maximum flux position

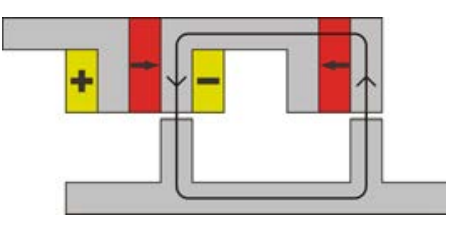

(b) Minimum flux position
Fig. 1. Flux distribution of coil

The studied structure is a three-phase 12/10 FSPM (see Fig. 2) with:

- 12 stator teeth

- 10 rotor teeth

- 12 ferrite permanent magnets (residual induction: 0.36T).

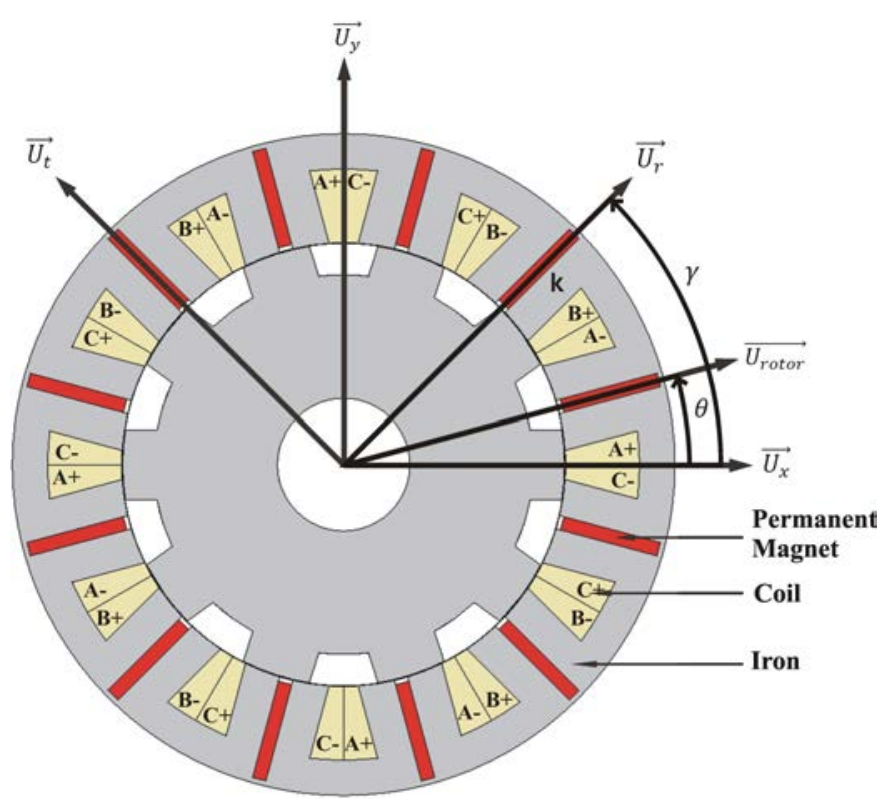

Fig. 2. 12/10 Flux Switching Permanent Magnet Machine 
In the following parts, two coordinate systems are considered. The static one is denoted by $R\left(O, U_{x}, U_{y}\right)$ and a particular point in the air-gap is marked using the rotative system, $R^{\prime}\left(O, U_{r}, U_{t}\right)$. The angle between these two systems is denoted $\gamma . \theta$ is used for the rotor position.

The magnet magnetizations $\overrightarrow{M_{k}}$ of permanent magnet $k$ are oriented in the direction $\vec{U}_{t}$ in $R^{\prime}$. They can be written:

$$
\overrightarrow{M_{k}}=\frac{(-1)^{k} B_{r}}{\mu_{0}} \overrightarrow{U_{t}}
$$

with $\mathrm{k}=0, \ldots, 11, B_{r}$ the residual induction, $\mu_{0}$ the vacuum permeability

The three-phase coils are mounted around the stator teeth. The injection currents are sinusoidal and in order to maximize the torque with minimum copper losses, they are chosen in phase with the electromotive forces (EMF):

$$
\left\{\begin{array}{r}
J_{A}=J \cdot \sqrt{2} \cdot k_{b} \cdot \sin \left(N_{r} \cdot \theta-\psi\right) \\
J_{B}=J \cdot \sqrt{2} \cdot k_{b} \cdot \sin \left(N_{r} \cdot \theta-\psi-\frac{2 \pi}{3}\right) \\
J_{C}=J \cdot \sqrt{2} \cdot k_{b} \cdot \sin \left(N_{r} \cdot \theta-\psi+\frac{2 \pi}{3}\right)
\end{array}\right.
$$

with $J_{A}, J_{B}, J_{C}$ the current densities, $J=5 \mathrm{~A} / \mathrm{mm}^{2}, k_{b}$ the winding factor (0.5), $N_{r}$ the number of rotor teeth $\left(N_{r}=10\right)$ and $\psi$ the angle of adjustment. For currents in phase with EMF $\psi=-60^{\circ}$. The geometrical parameters appear on TABLE I.

\begin{tabular}{|r|c|}
\hline Outer radius & $75.05 \mathrm{~mm}$ \\
\hline Rotor radius & $50.05 \mathrm{~mm}$ \\
\hline Air gap & $0.2 \mathrm{~mm}$ \\
\hline rotor tooth width & $15.70 \mathrm{~mm}$ \\
\hline stator tooth width & $8.25 \mathrm{~mm}$ \\
\hline Permanent Magnet width & $3.10 \mathrm{~mm}$ \\
\hline
\end{tabular}

TABLE I

FSPM PARAMETERS

\section{MAGnetic STRESS IN THE FSPM MACHINE}

At the interface between two surfaces, the magnetic stresses can be written as:

$$
\vec{\sigma}=\sigma_{n} \cdot \overrightarrow{U_{r}}+\sigma_{t} \cdot \overrightarrow{U_{t}}
$$

where $\sigma_{n}$ represents the normal stress and $\sigma_{t}$ the tangential one. It can be shown that the normal stress is predominant at an interface between two materials. The following approximation is thus available:

$$
\vec{\sigma} \simeq \sigma_{n} \cdot \overrightarrow{U_{r}}
$$

Using the expression of the Maxwell tensor in these coordinate systems, we can deduce the expressions of the normal stress[6]:

$$
\sigma_{n}=\frac{1}{2}\left(b_{n}^{2} \cdot\left(\frac{1}{\mu_{1}}-\frac{1}{\mu_{2}}\right)-h_{t}^{2} \cdot\left(\mu_{1}-\mu_{2}\right)\right)
$$

with $\mu_{1}$ and $\mu_{2}$ the permeability of both materials, $b_{n}$ the normal induction and $h_{t}$ the tangential magnetic field. The permeability of material 1 (air or permanent magnets) is very small compared to the permeability of the material 2 (iron) and then [7]:

$$
\sigma_{n} \simeq \frac{b_{n}^{2}}{2 \mu_{0}}
$$

Stresses are oriented from the highest permeability material (iron) toward the weak permeability medium (air).

\section{A. Components of normal stress in the air}

Now, we are interested in the normal stress in the air-gap. Using Eq. 6, we will specify the components of the normal induction in the air-gap. For this, consider the case where FSPM machine is without rotor. When there is no saturation of the magnetic circuit, the normal magnetic induction in the air in function of $\gamma$ (see Fig. 2 for notations) can be divided in two terms:

$$
b_{n}(\gamma, i, t)=b_{P M}(\gamma)+b_{i}(\gamma, i, t)
$$

with $b_{P M}$ the induction created by the permanent magnets which depends only the position $\gamma, b_{i}$ the induction created by current $i$ at frequency $f$. This induction can be written:

$$
b_{i}(\gamma, i, t)=K_{i}(\gamma) \cdot i(t)
$$

with :

$$
i(t)=I \cdot \sqrt{2} \cdot \cos (2 \pi \cdot f \cdot t-\psi)
$$

Normal stress can be written:

$$
\begin{aligned}
\sigma_{n}(\gamma, t)= & \frac{1}{2 \mu_{0}}\left[b_{P M}(\gamma)^{2}+K_{i}(\gamma)^{2} \cdot I^{2}\right. \\
+2 \sqrt{2} & \cdot I \cdot b_{P M}(\gamma) \cdot K_{i}(\gamma) \cdot \cos (2 \pi \cdot f \cdot t-\psi) \\
& \left.+K_{i}(\gamma)^{2} \cdot I^{2} \cdot \cos (2 \pi \cdot(2 f) \cdot t-2 \psi)\right]
\end{aligned}
$$

For a position $\gamma$ in the air, $b_{P M}(\gamma)$ et $K_{i}(\gamma)$ are constant. Eq. (10) becomes:

$$
\begin{aligned}
\sigma_{n}(\gamma, t)=A(\gamma)+ & B(\gamma) \cdot \cos (2 \pi \cdot f \cdot t-\psi) \\
& +C(\gamma) \cdot \cos (2 \cdot \pi \cdot(2 f) \cdot t-2 \psi)
\end{aligned}
$$

with:

$$
\left\{\begin{array}{r}
A(\gamma)=\frac{b_{P M}(\gamma)^{2}+K_{i}(\gamma)^{2} \cdot I^{2}}{2 \mu_{0}} \\
B(\gamma)=\frac{\sqrt{2} \cdot I \cdot b_{P M}(\gamma) \cdot K_{i}(\gamma)}{\mu_{0}} \\
C(\gamma)=\frac{K_{i}(\gamma)^{2} \cdot I^{2}}{2 \mu_{0}}
\end{array}\right.
$$

Normal stress has three components:

- A constant component due to permanent magnets (A)

- A component at frequency $f$ due to the interaction between permanent magnets and current (B)

- A component at frequency $2 f$ due to current $(C)$

We presented the different contributions to the magnetic stress, we will present the normal stresses in the complete FSPM machine by FEM analysis. 


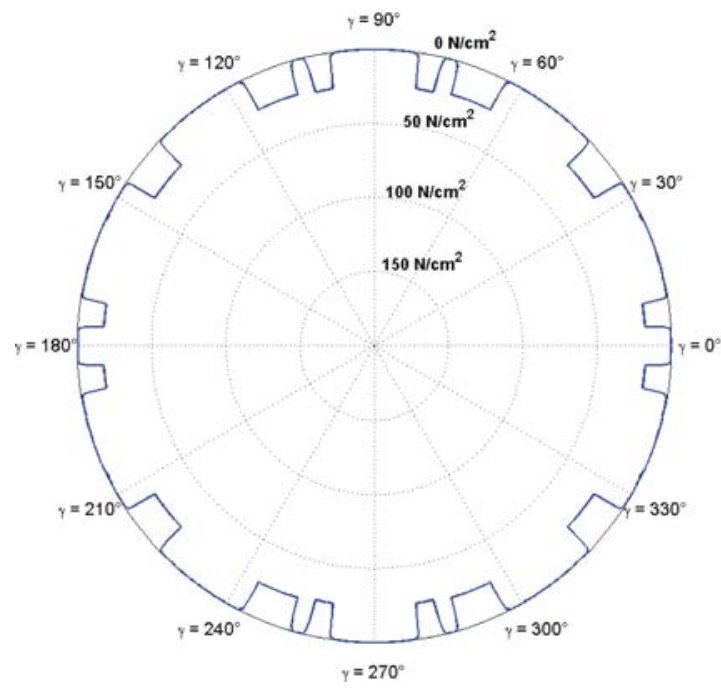

(a) normal stress with FSPM unload

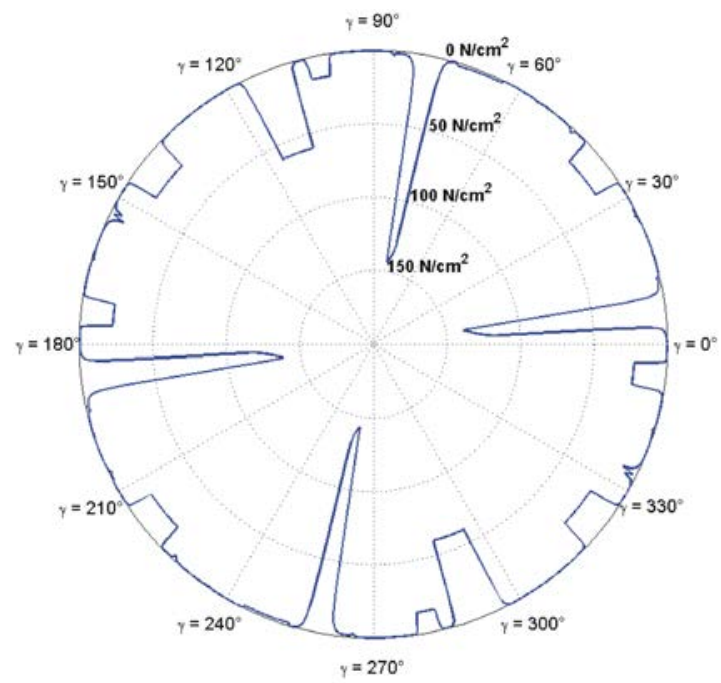

(b) normal stress with FSPM load $\left(\psi=-60^{\circ}\right)$

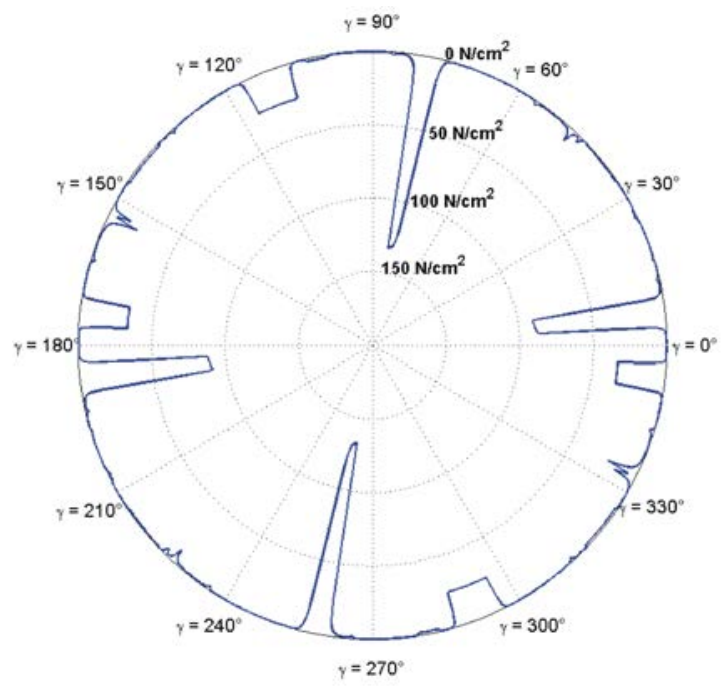

(c) normal stress with FSPM load $\left(\psi=-15^{\circ}\right)$

Fig. 3. Normal stresses at the air / teeth interfaces in polar coordinates $\sigma_{n}$ for $\theta=0^{\circ}$

\section{B. Normal stress at the stator teeth}

In the air-gap, normal stresses (the one leading to deformations) are much higher than tangential ones (leading to the creation of the torque). Thus, we will focus exclusively on the former stresses denoted by $\sigma_{n}$. The forces created tend to reduce the air-gap thickness. As a consequence, they are directed along $-\overrightarrow{U_{n}}$. In order to quantify those particular stresses, a finite element analysis has been used which simulates the behavior of our FSPM device and calculates the magnetic induction in the machine. Knowing the latter, we can deduce the normal stress appearing when the machine is unloaded and loaded (with differents $\psi$ ). Corresponding results are presented in Fig. 3 where the stress have been plotted for a particular position of the rotor $\left(\theta=0^{\circ}\right)$.

Some remarks can be done:

- Firstly, normal stress exists even during an unloaded operation of the machine $(\mathrm{J}=0)$, see Fig. 3 (a), and these stresses become maximal when the stator teeth face the rotor ones

- Secondly, when the FSPM machine is loaded $(J=$ $5 \mathrm{~A} / \mathrm{mm}^{2}$ ), see Fig. 3 (b) and Fig. 3 (c), because of the coils / permanent magnets interaction, the magnetic induction can be null even when the stator teeth face the rotor ones. When this phenomenon occurs, there is no more normal stress

- Thirdly, when the machine is loaded, normal stresses can locally raise up to $140 \mathrm{~N} / \mathrm{cm}^{2}(1.9 \mathrm{~T})$

- Finally, when $\psi$ varies, the normal stresses varies too. The peak value is higher when the currents are in phase with EMF (maximum torque for $\psi=-60^{\circ}$ ) and they decrease when $\psi$ differs from $-60^{\circ}$.

We have just presented the normal stress in the machine for a particular position of the rotor. Now, we study the variation of these stress while the rotor is revolving (with or without load). For this purpose, we will focus on the stress located on a single tooth and the mean stress calculated on that tooth will be plotted for an electrical period $\left(36^{\circ}\right)$. From the results presented in Fig. 4, an important point has to be highlighted. Indeed, for a loaded machine, the harmonic content appears richer and, as a consequence, more harmonic ranks are excited, leading to a richer spectrum of the acoustic noise.

A characterization has been performed of all stress which are created during a operation of the FSPM machine and particularly of their harmonic spectrum. Now, we will quantify the spectrum content, especially the frequencies being excited by the stress. We can notice that they are directly related to the angular speed of the rotary. To write explicitly the relation between those two variables, we use equation 13 which leads to:

$$
f_{\text {exc }}=k \cdot \frac{N_{r} \cdot \Omega}{60}
$$

with:

$\mathrm{k}$ : harmonic rank

$N_{r}$ : number of teeth rotor (10)

$\Omega$ : angular speed (en tr/min). 


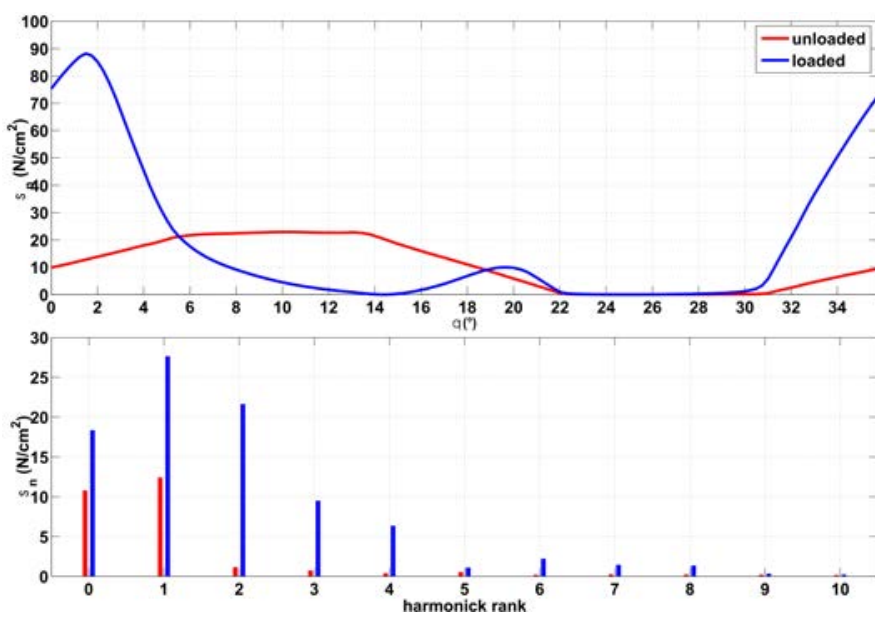

Fig. 4. Normal stresses at iron / air-gap interface along $U_{r}$ with and without load when FSPM is revolving

\section{Stresses located on the permanent magnets}

In this section, we will focus on the stress created at the iron / permanent magnets interfaces. The considered notations are represented in Fig. 5. The normal stresses appear in Fig. 6. We can observe that these particular stresses are very weak

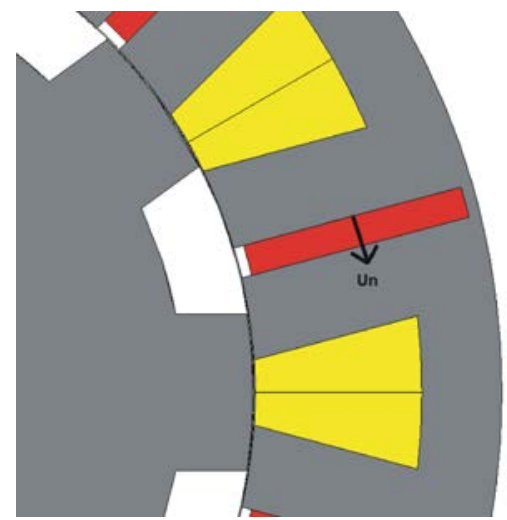

Fig. 5. Notations for stresses created at the iron / permanent magnets interface

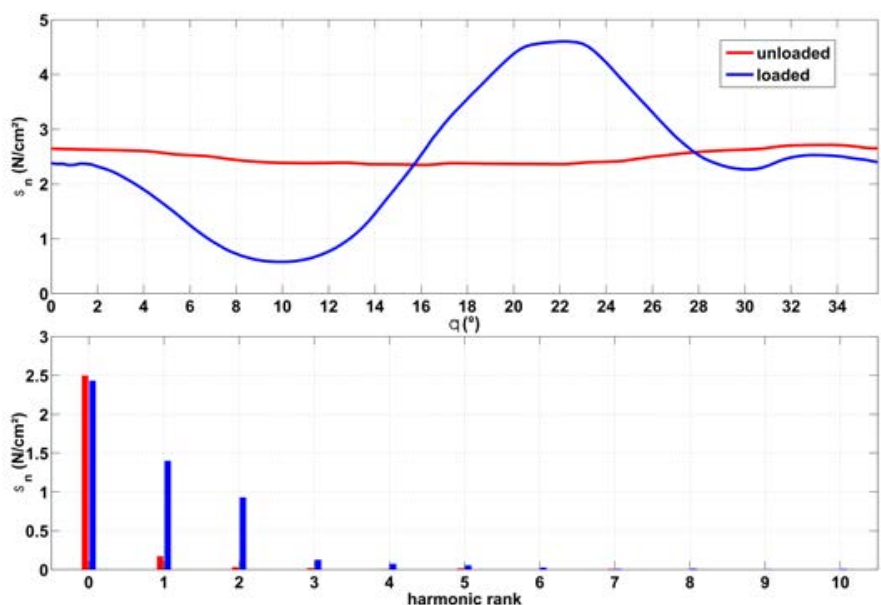

Fig. 6. Normal stress at iron / permanent magnet interface along $U_{n}$ with and without load when FSPM is revolving compared to those calculated at a tooth / air-gap interface. Nevertheless, we can see a non-negligible variation of these variables which will necessarily generate acoustic vibrations.

\section{VIBRATIONAL AND MODAL ANALYSIS}

In the previous section, we have observed the normal stresses in the FSPM machine. Now we will analyse the effect of these stresses on the deformation of the FSPM machine.

\section{A. Expression of the deformation of the stator teeth}

We will write the deformation of the stator teeth under the effect of the magnetic stresses. Again, the rotor is removed and see Fig. 2 for notations. Let consider a surface element $S$ with $x$ the displacement, $m$ the mass of machine and $k$ the stiffness ( $\lambda$ the viscosity is not considered). The dynamic equation [8] can be written:

$$
m \cdot \frac{d^{2} x}{d t^{2}}+k \cdot x=\sigma_{n} \cdot S
$$

with $\sigma_{n}$ the stress obtained by Eq. 11. We have:

$$
\begin{array}{r}
m \cdot \frac{d^{2} x}{d t^{2}}+k \cdot x=A \\
+S+B \cdot S \cdot \cos (2 \pi \cdot f \cdot t-\psi) \\
+C \cdot S \cdot \cos (2 \pi \cdot(2 f) \cdot t-2 \psi)
\end{array}
$$

The solution of this equation is:

$$
\begin{aligned}
x(t) & =K \cdot \cos \left(\sqrt{\frac{k}{m}} \cdot t+\alpha\right) \\
& +\frac{A \cdot S}{k}+\frac{B \cdot S}{k-m \cdot 4 \pi^{2} \cdot f^{2}} \cdot \cos (2 \pi \cdot f \cdot t-\psi) \\
& +\frac{C \cdot S}{k-m \cdot 4 \pi^{2} \cdot(2 f)^{2}} \cdot \cos (2 \pi \cdot(2 f) \cdot t-2 \psi)
\end{aligned}
$$

with $K$ and $\alpha$ constants to be determined. There are two resonance frequencies:

$$
\begin{gathered}
f_{1}=\frac{1}{2} \cdot \frac{1}{2 \pi} \sqrt{\frac{k}{m}} \\
f_{2}=\frac{1}{2 \pi} \sqrt{\frac{k}{m}}
\end{gathered}
$$

When current frequency $\mathrm{f}$ is equal to $f_{1}$, the deformation will be at the double frequency current. When current frequency f is equal to $f=f_{2}$, the deformation will be at the current frequency. Therefore, an eingenmode appears for two different current frequencies. The next part will specify the eigenfrequencies of the stator of the FSPM machine.

\section{B. Vibrational eigenmodes of the structure}

We realized a 2D modal analysis of the stator using FEM analysis with a commercial solver ANSYS. The machine is modeled as ferromagnetic sheets and permanent magnets with their mechanical characterictics. The method is based on the spatial discretization [9] of the structure using triangle meshes with $\mathrm{n}$ nodes. Let us denote by: $q(t)=\left[q_{1}, q_{2}, \ldots, q_{n}\right]^{T}$ the 
nodal displacement array, $[M]$ and $[K]$ are respectively the mass and rigidity matrices $(n \times n$ dimension). The dynamic equation thus takes the following form:

$$
[M] \cdot \frac{d^{2} q(t)}{d t^{2}}+[K] \cdot q(t)=0
$$

which admits harmonic solutions:

$$
q(t)=p \cdot \cos (\omega \cdot t-\phi)
$$

where $p=\left[p_{1}, p_{2}, \ldots, p_{n}\right]^{T}, \omega$ is the pulsation, $\phi$ the phase. In order to determine eigenfrequencies, we solve:

$$
\left([K]-\omega^{2} \cdot[M]\right) \cdot[U]=0
$$

with $[U]$ eigenvector. The first resonant modes of the stator are plotted in Fig. 7. We can observe mode $2(997 \mathrm{~Hz})$, mode $3(2665 \mathrm{~Hz})$, mode $4(4757 \mathrm{~Hz})$ and mode $5(6898 \mathrm{~Hz})$.

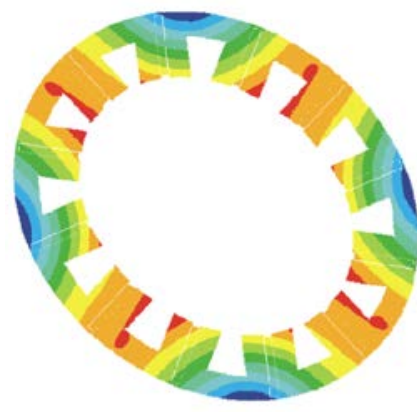

(a) Mode 2: $997 \mathrm{~Hz}$

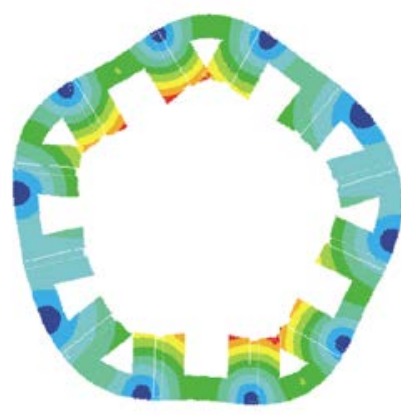

(c) Mode 4: $4757 \mathrm{~Hz}$

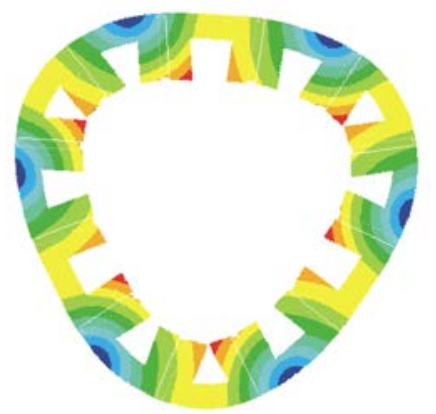

(b) Mode 3: $2665 \mathrm{~Hz}$

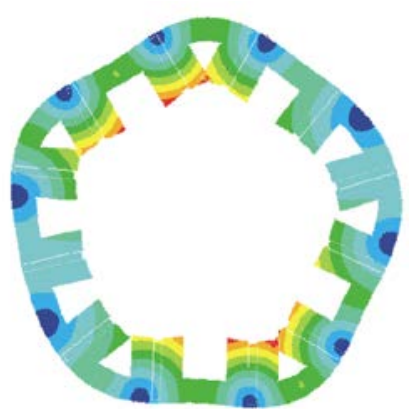

(d) Mode 5: $6898 \mathrm{~Hz}$
Fig. 7. Eigenmodes of the FSPM machine

\section{Modes excited by the normal stresses}

We have just detailed the frequencies of the resonant modes of our structure. If some components of the stress spectrum coincide with those particular frequencies, the machine resonates. However, when the machine is feeded, a particular distribution of stresses may lead to the suppression of some modes. In order to observe this phenomenon, the spatial Fourier series of the normal stress with load (see Fig. 4) is calculated. The first coefficients of this series are represented in Fig. 8. The vibrational modes which could be excited are the number 2 and 4 , and the 3 and 5 cannot be excited.

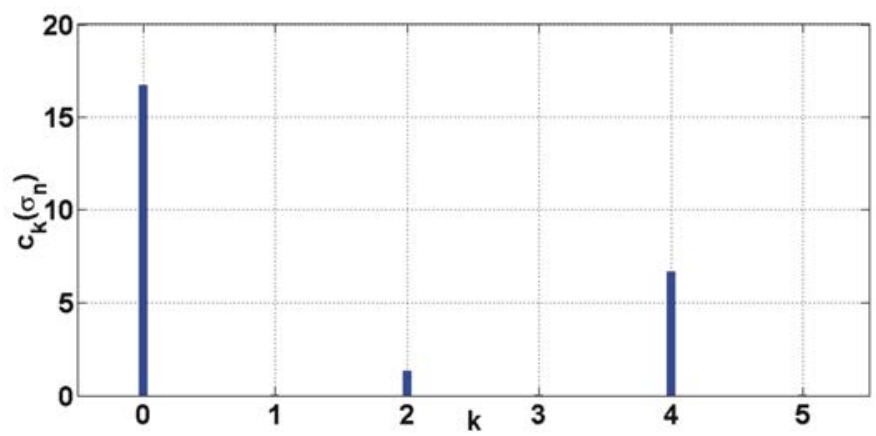

Fig. 8. $\sigma_{n}$ at the air / stator teeth interface Fourier serie coefficients

\section{Experimental measures}

We measured the vibrations of the FSPM machine. The rotor is removed. A piezoelectric accelerometer is placed on the stator on the top of a tooth in order to measure the acceleration in this point (see Fig. 9). We have supplied a single coil of a single phase. For such kind of excitation, all modes of deformation can be measured. Finally the experimental vibration function of the current frequency is presented Fig. 10.

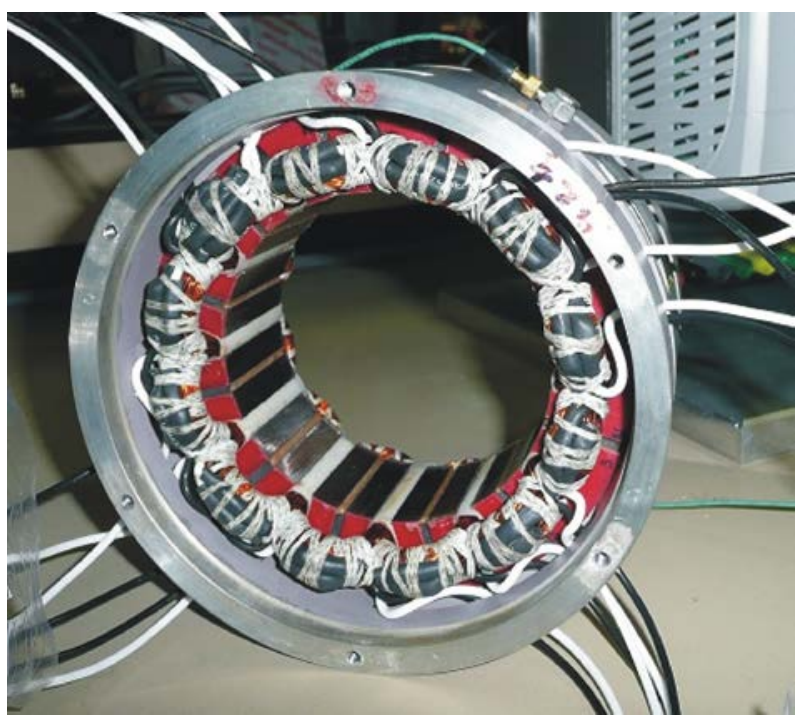

Fig. 9. FSPM stator and accelerometer

Mode 2 obtained by FEM analysis is correctly measured. Mode 4 obtained by FEM analysis is underestimated. Nevertheless, in this figure, we can note a large number of eigenfrequencies. For FSPM, there is a pair of eingenfrequencies for each mode of vibration. Difference between eigenfrequencies determined by finite element simulation and experimental can be explained by frame. It depends on the mechanical linkage between stator and frame.

\section{CONClusion}

In this paper we analysed magnetic forces and vibrational behavior of a FSPM machine. We expressed the different terms of the magnetic stresses in the FSPM machine and we observed the normal stress at two locations: at the air / teeth 


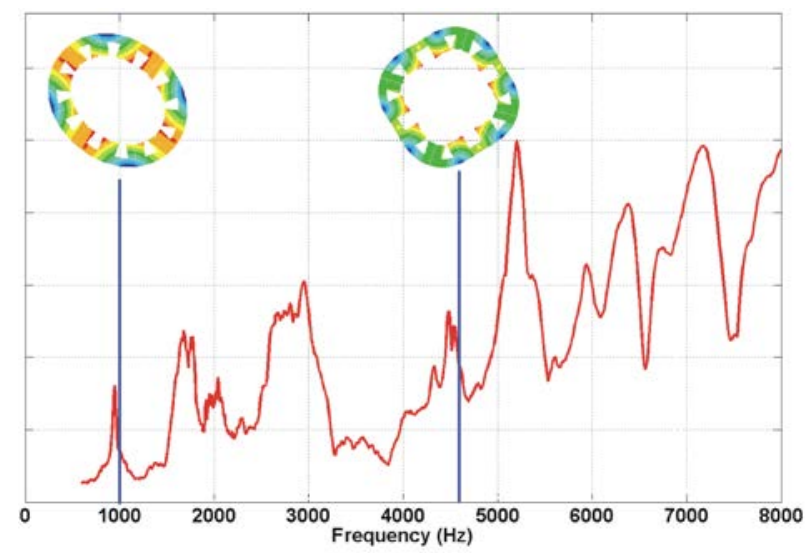

Fig. 10. Vibration of the structure

stator interface and at the iron / permanent magnet interface using FEM analysis when the machine is unloaded and loaded. Then we predicted the deformation of the structure in a simple case without rotor and we realized a modal analysis by finite elements method. Finally we measured the vibrations of a FSPM machine at a point of the structure and we justified that these vibrations were at the current frequency or double current frequency.

\section{REFERENCES}

[1] B.L.J. Gysen, E. Ilhan, K.J. Meessen, J.J.H. Paulides and E.A. Lomonova Modeling of Flux Switching Permanent Magnet Machines With Fourier Analysis, IEEE Transactions Magnetics, vol. 46, no. 6, june 2010

[2] E. Hoang, A. H. Ben-Ahmed and J. Lucidarme, Switching flux permanent magnet polyphased synchronous machines, Proc. 7th Euro. Conf. Power Electronic and Applications, 1997, pp. 903-908

[3] Z. Zhu, Y. Pang, D. Howe, S. Iwasaki, R. Deodhar, and A. Pride, Analysis of electromagnetic performance of flux-switching permanentmagnet Machines by nonlinear adaptive lumped parameter magnetic circuit model, IEEE Transactions on Magnetics, vol. 41, no. 11, pp. 42774287, november 2005

[4] W. Cai, P. Pillay, Resonant Frequencies and Mode Shapes of Switched Reluctance Motors, IEEE Transactions on Magnetics, vol. 16, no. 1, march 2001

[5] J. Ojeda, M. Gabsi, M. Lecrivain and X. Mininger, Noise reduction using piezoelectric active control on high speeds switched reluctance drives, IEEE Transactions on Magnetics, september 2007

[6] J. Li, H. Sun, S. Fan and Y. Liu, Switched Reluctance Motor's Magnetic Force Analysis and the Drive System Simulation Verification, 2010 2nd International Conference on Industrial and Information Systems

[7] Z. Zhu, Z. Xia, L. Wu and G. Jewell, Analytical modeling and finite-element computation of radial vibration force in fractional-solt permanent-magnet brushless machines, IEEE Trans. Ind. Appl., vol. 46, no. 5, pp. 1908 1919, sept.-oct. 2010

[8] M. N. Anwar and I. Husain, Radial Force Calculation and Acoustic Noise Prediction in Switched Reluctance Machines, IEEE Transactions on Magnetics, vol. 36, no. 6, december 2000

[9] C.G.C. Neves, R. Carlson, N. Sadowski, J.P.A. Pastos, Experimental and Numerical Analysis of Induction Motor Vibrations, IEEE Transactions on Magnetics, vol. 35,no. 3, may 1999 